\title{
Uma arquitetura pedagógica apoiada em tecnologias da informação e comunicação: pro- cesso de aprendizagem em química no ensino médio
}

Edson Luiz Lindner

Orientador(a): Profa. Dra. Léa da Cruz Fagundes

Coorientador: Prof. Dr. Milton Antônio Zaro

Data da defesa: 16 de julho de 2009

A necessidade urgente de mudanças no Ensino Médio do Brasil motivou o pesquisador desta tese a propor mudanças na forma tradicional de se trabalhar a Química com os estudantes. Com a evolução das tecnologias de informação e comunicação, é necessário que o cidadão seja incluído na cultura digital para que possa fazer parte da sociedade globalizada dos dias atuais. Assim, também é tarefa da escola a busca da inclusão dos sujeitos nessa cultura digital. A utilização das novas tecnologias é importante e deve ser considerada quando se planejam atividades de aprendizagem com os alunos da Escola Básica. O principal objeto de pesquisa dessa tese foi o estudo dos processos cognitivos que envolvem aspectos da aprendizagem da Química com o uso dessas tecnologias. Procurou-se verificar como uma Arquitetura Pedagógica orientada para os alunos, contendo atividades experimentais, produção de vídeos e elaboração de modelos digitais no ambiente Squeak-Etoys, pode contribuir para a construção do conhecimento químico. Entende-se a Arquitetura Pedagógica como um conjunto de estratégias, dinâmicas de grupo, softwares educacionais e ferramentas de apoio à cooperação que possam favorecer a aprendizagem. A análise dos processos vivenciados pelos sujeitos da pesquisa foi fundamentada pela Epistemologia Genética de Jean Piaget. A partir das análises dos dados da pesquisa pretende-se propor orientações para as ações pedagógicas com o uso de ambientes digitais, onde ocorram processos nos quais os sujeitos possam representar, ampliar e consolidar o seu conhecimento científico.

Palavras-chave: Aprendizagem em Química. Arquitetura Pedagógica. Utilização das TIC's. Ambientes Digitais. Ensino Médio Inovador. Epistemologia Genética.

Referência:

LINDNER, Edson Luiz. A construção do conhecimento, as intervenções metodológicas e os novos saberes e fazeres na cultura digital rural - Orientadora: Léa da Cruz Fagundes. Coordenador: Milton Antônio Zaro - 2009. Tese (doutorado) - Programa de Pós-Graduação em Informática na Educação, Centro de Estudos Interdisciplinares em Novas Tecnologias da Educação, Universidade Federal do Rio Grande do Sul, 2009, Porto Alegre. 